\title{
A research on the security of wisdom campus based on geospatial big
}

\author{
data \\ Wang Haiying \\ School of Land and Resource \\ China West Normal University \\ Nanchong, China \\ e-mail: wanghaiying8228@163.com
}

\begin{abstract}
There are some difficulties in wisdom campus, such as geospatial big data sharing, function expansion, data management, analysis and mining geospatial big data for a characteristic, especially the problem of data security can't guarantee cause prominent attention increasingly. In this article we put forward a data-oriented software architecture which is designed by the ideology of orienting data and data as kernel, solve the problem of traditional software architecture broaden the campus space data research, develop the application of wisdom campus.
\end{abstract}

Keywords: Wisdom campus; Geospatial Big Data; DOA

\section{INTRODUCTION}

The mobile wave which represented by intelligent terminals, mobile Internet and internet of things not only impact on the network construction of wisdom campus, but also reverse the idea and direction of the information system construction, promote the generation and development of wisdom campus. The $80 \%$ information obtained by human activities is related to geographical location, a large amount of data related to the location of time and space has become geospatial big data. The big data has the characterization of volume, variety, velocity and veracity [1], more important because of its hidden added value, it has attracted the high attention of designers of wisdom campus.

\section{CONCEPTUAL FRAMEWORK}

\section{A. Wisdom campus}

Wisdom campus is the senior form of university informatization, it is further expansion and ascension of digital campus, it integrate cloud computing, mobile Internet, big data, knowledge management and other emerging information technologies. It makes intelligent open education teaching environment for teachers and students and it is convenient and comfortable living environment [2]. Wisdom campus has the characteristics of high-speed Internet network used, intelligent terminals widely used, teamwork convenience adequately, collective knowledge coexistence and co-prosperity, business application intelligent integration, external intelligence mastery, etc. The main objectives of it are intelligent talent cultivation, intelligent scientific research, intelligent social service and intellectual culture inheritance and innovation.

\section{B. Geospatial Big Data}

Geospatial big data refers to data directly or indirectly related to a particular location on earth, including natural geographic data and socio-economic data. Geospatial big data includes land cover types, topography data, soil data, hydrological data, vegetation data, resident data, administrative level, social and economic aspects of the data, and so on. Geospatial big data is used for the urban operation services in intelligent transportation, energy conservation and emissions reduction, emergency response, for personal life in social interaction, personalized information push, intelligent driving service, for the 
enterprise in the enterprise scheduling, the respect such as the position of marketing economic services.

\section{THE ADVANTAGE OF WISDOM CAMPUS BASED ON GEOSPATIAL BIG DATA}

\section{A. The content is more comprehensive and detailed}

The demands of geographic information transform from the original map which is more general to the direction of more and more comprehensive, detailed and accurate, intuitive and beautiful, low degree of abstraction and comprehensive in development. So the scale of map is more and more big, the geographic entity attribute information is more and more detailed. In addition to the attribute information of geographical entity requirements also increased, it is not only to distinguish the parts of basic properties, but also other kinds of attribute information of city such as the ownership and material should be expressed. This is the need of intensive planning management, refined service management and precise control of governance. In short, the big data of geospatial must be comprehensive and detailed [3].

\section{B. Data visualization display}

The visualizations of time and spatial data add time and spatial information to the elements, and the biggest change is the combination dynamic display of maps and data. The main forms of visualization contains diagram showing and map visualization. Diagram showing based on chart and geographical location, the change of location will change the display of chart data; A map visualization is the applications of time information and knowledge mining. The form of the map visualization expression can be divided into three categories: spatial characteristics rules, spatial relationships and spatial evolution law, each of the different types of knowledge map visualization expression are different. Map visualization of time and spatial data generally adopt the way of map rendering, the spatial characteristics of the rules, spatial clustering classification results display, application of the change of the timeline, display space evolution law [4-6].

\section{The convergence of today's data and past data}

As the source of geographic information becomes more and more abundant, the demand for geographic information has been developed from the original management query to the application of mining analysis. With the wide application of remote sensing technology, all organizations has established the GIS industry, the demand of geographic information services transform from the original query management gradually into analysis and knowledge mining with the purpose of aid planning and decision making. Traditional spatial database is established in accordance with the different times different versions of the spatial database, it is difficult to reflect the process of geographic space changes over time clearly, and it is not easy to analyze the law of the spatial data changes over time [7]. So we should to build a time scale of temporal spatial database which can afford a geographical space, according to the spatial database the process of the formation, development and disappear is clearly, then we can analyze the process of the geographic space changes over time.

\section{THE SUPPORT SYSTEM OF WISDOM CAMPUS BASED ON GEOSPATIAL BIG DATA}

The overall architecture of wisdom campus based on geospatial big data is shown in figure 1.The security system of wisdom campus based on geospatial big data includes the physical security, network security, data security and content security, the security system guarantee for the safe, stable and efficient operation of wisdom campus. 


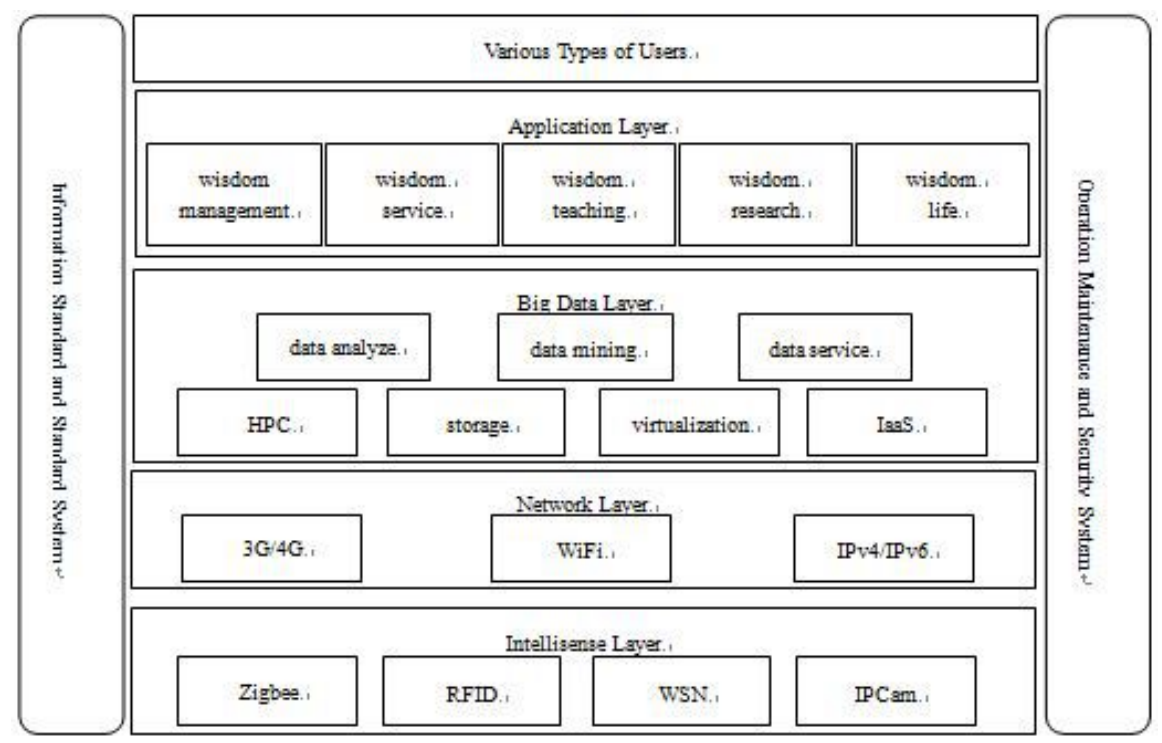

Figure 1. Architecture of wisdom campus.

In order to ensure the data security of geospatial big data, we adopt the data-based and data-oriented architecture [8], as shown in figure 2. The architecture of DOA is designed by the ideology of orienting data and data as kernel. The architecture is composed by the data register center (DRC), data authority center (DAC), data exception control center (DEC) and data application units (DAUs).

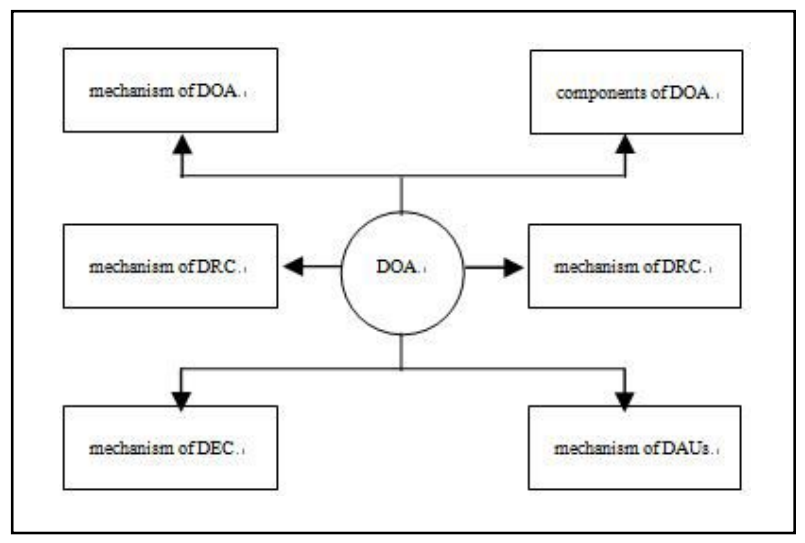

Figure 2. Content of DOA.

\section{A. Basic principles of data security under DOA}

DOA is designed by the ideology of orienting data and data as kernel. The data has a security attribute to identity the owner, friend, stranger, and enemy of the data. DOA considers security issues from a data perspective to ensure data integrity, confidentiality, and availability, so the data is inherently encrypted and authorized to use. The data has a self-protection feature with different encryption levels and depths. The use of data is authorized. Data has two states, state data in storage and transmission, application state in authorization. The data state is the encryption state, and the application data is the decryption state. DOA provides a kind of encryption and authorization mechanism, ensure that the data in storage and transport cannot access and use, when authorized users access data or use data, the feel of the data encryption and decryption process is transparently.

B. The composition of DOA

1) The data register center 
Various types of data and generalized data are registered in the data register center, form logical data pools that facilitate the access to data. Its function involved registrating information data definition, data attribute information, data classification, metadata standards, registration method of different kinds of data, data index, index of metadata, data retrieval, a distributed deployment, etc.

2) The data authority center

The data authority center manages the access to rights management. Its functions involved but not limited to data security attribute definition, legitimacy identification data, data access definition, user privileges authentication, authorization, user authorization, data authorization and public key infrastructure, data transparent encryption mechanism, the efficient data encryption algorithm, etc.

3) The data exception control center

When the data redundancy in distributed environment the data exception control center process the data consistency. Its functions involved but not limited to data maintenance, adaptive management, anomaly detection and processing, inspection, abnormal and conflict found that synchronous processing, redundant processing, load balance, etc.

4) The data application units

The data application units are a series of application on data resource pool unit module, management and service application. The DAUs meet requirements of various applications for users rapidly. Its functions involved providing different data function unit according to the data of different data types, data services unit to push the data, data encryption unit, data invocation unit, data combination unit, data visualization unit, data processing unit, etc.

\section{CONCLUSION}

This paper adopts the ideology of orienting data and data as kernel, the uniform definition and management of data is completed by DRC, DAC, DEC, the management of a variety of applications and services is realized by DAUs. DOA set up a set of mechanism from data protection to authorization application. DOA can solve the problems and challenges in the security aspects of information sharing, data management and other geospatial data in wisdom campus of the big data era effectively.

\section{ACKNOWLEDGMENT}

This paper thanks the support of Sichuan education department project, Item no. : 16ZB0171.

\section{REFERENCE}

[1] Schönberger, V. M. and Cukier K, Big data: A Revolution That Will Transform How We Live, Work, and Think, Eamon Dolan: Houghton Mifflin Harcourt, 2013, pp.12-23.

[2]Jiang Dongxing, Fu Xiaolong, Yuan Fang, Wu Haiyan and Liu Qixing, Discussion on the construction of wisdom campus in universities under the background of big data, Journal of East China Normal University, 2015(3).pp.119-131.

[3]Ai Tinghua, Development of Cartography Driven by Big Data, Journal of Geomatics, 2016, 41(2),pp.1-7.

[4]Li Deren, Wang Shuliang and Li Deyi. Theory and application of spatial data mining, Beijing: Science Press, 2006, pp.29-36.

[5]Xie Zhipeng. Research on knowledge discovery based on concept lattice model, Hefei: Hefei University of Technology, 2001, pp.36-38.

[6]Xie Zhipeng and Liu Zhoutian, A Fast Incremental Algorithm for Building Concept Lattice, CHINESE J. COMPUTERS, 2002, 25(5), pp.490-496.

[7]Luo Jiancheng, Hu Xiaodong, Wu Wei and Wang Bo, Collaborative Computing Technology of Geographical Big Data, Journal of Geo-information Science, 2016,18(5),pp.590-598.

[8]Miao Fang, Discussion of data-oriented software architecture, Journal of Frontiers of Computer Science and Technology, 2016, 10(10), pp.1351-1364. 